\title{
Los procesos geográficos de concentración en las centralidades étnicas
}

\author{
Pau Serra del Pozo \\ Universidad Internacional de Cataluña \\ pserra@cir.uic.es
}

\section{Resumen}

La combinación de los diversos procesos (concentración o dispersión, diversidad o especialización, monoetnicidad o multietnicidad) da lugar a diversos tipos de espacios de negocios étnicos. En este primer artículo se introducirá el concepto de «centralidades étnicas». La metodología se basa en la revisión de la literatura reciente sobre los paisajes de los negocios étnicos en áreas metropolitanas en Norteamérica, Australia y Europa y en la investigación y exploración del propio autor en diversos espacios de negocios étnicos.

Palabras clave: centralidades étnicas, emprendedores inmigrantes, procesos de concentración, diversidad comercial

\footnotetext{
Abstract:

The combination of various processes (concentration or dispersion, diversity or specialization, monoethnicity or multiethnicity) shapes different types of ethnic business areas. This first paper introduces the concept of «ethnic downtowns». The papers' methodology is based upon a review of recent literature on landscapes of ethnic businesses in metropolitan North America, Australia and Europe and the author's own research and exploration in several ethnic businesses areas.

Keywords: ethnic business districts, immigrant entrepreneurs, processes of concentration, commercial diversity
} 


\section{1. «Centralidades étnicas»ः ¿revitalización urbana o guetización?}

El presente trabajo trata de establecer y describir una tipología de los espacios donde se implantan los negocios étnicos, es decir, las actividades económicas dirigidas por emprendedores pertenecientes a grupos étnicos, sobre todo inmigrantes, pero también a otras minorías, ${ }^{1}$ en ciudades tanto de sociedades avanzadas como de sociedades en desarrollo. ${ }^{2}$ Estos espacios los he denominado centralidades étnicas, centralidades étnicas minoritarias, centralidades multiétnicas minoritarias, centralidades étnicas especializadas y zonas de emprendedores étnicos minoritarios. Estos cinco espacios de negocios étnicos se configuran a partir de procesos geográficos de concentración o de dispersión, usados por los inmigrantes como verdaderos recursos espaciales en sus estrategias empresariales. Los cinco tipos de espacios se caracterizan, además, por la diversidad o especialización de las actividades de los emprendedores étnicos.

Desde el punto de vista metodológico, el artículo se basa en una revisión de la literatura reciente sobre los paisajes de los negocios étnicos en áreas metropolitanas en Norteamérica, Australia y Europa, así como en mi propia investigación y exploración en diversos espacios de negocios étnicos. En este artículo me ocuparé exclusivamente de las centralidades étnicas. En otro artículo posterior describiré los otros cuatro espacios de negocios étnicos.

La inmigración internacional, al menos en Estados Unidos, es sobre todo un fenómeno urbano: en 2000, el 94\% de los inmigrantes de ese país residía en áreas metropolitanas (Singer, 2006). En este sentido, algunos autores han insistido en los efectos de revitalización en centros urbanos grandes o pequeños o en zonas suburbanas hasta entonces degradados que ha conllevado la aparición de concentraciones de negocios étnicos en las ciudades, sobre todo de pequeños comercios. ${ }^{3}$ Esas concentraciones de emprendedores inmigrantes configuran las denominadas «centralidades minoritarias» (Raulin, 2000), «centralidades interétnicas» (Ferrer Regales, 2006) u otras expresio-

1 Para las definiciones de «negocio étnico» u otras parecidas, como «emprendedor inmigrante», véase Light y Gold (2000), Ma Mung (1996), Checa y Arjona (2006), Beltrán et alii (2007), Rath (2002), Dinh (2006) y Solé et alii (2005 y 2007). Tal vez haya tantas definiciones como investigadores se ocupan de estos temas. Para Rath (2002), no hay que preocuparse excesivamente por este debate, sino más bien conformarse de manera pragmática con los diferentes pareceres de autores de diferentes países y contextos. A este respecto, se pueden citar contextos socioculturales tan dispares como los de la República Sudafricana, Senegal, Estados Unidos, España, Chile, India o China. Rath destaca con sentido del humor que ni siquiera en el manual Etbnic Economies de Light y Gold (2000) existe una explicación sobre la «etnicidad». En cualquier caso, como punto de partida, para Barth (1969, citado por Raulin, 2000, y por Torres, 2007), los grupos étnicos se manifiestan diferenciándose de otros grupos con los que conviven a partir de algunos rasgos socioculturales.

2 Bredeloup y Bertoncello (2006) describen la aparición de comercios chinos en las capitales de África occidental.

3 Shaw et alii (2004), Kaplan y Li (2006b), Light y Gold (2000), Buckley (2007), Lo (2006), Kaplan (1998), Teixeira (2006), Li et alii (2006), Loukaitou-Sideris (2002), Godfrey (2007), Rekers y van Kempen (2000), Rath (2002, 2007). 
nes similares. ${ }^{4}$ «Centralidades étnicas» es la expresión que prefiero utilizar, ${ }^{5}$ o bien ethnic downtowns, en inglés.

A este respecto, Alberts (2006) señala que lo que con el paso de los años se convertiría en la próspera Little Havana de Miami era antes de la llegada de los cubanos en la década de 1960 un barrio en creciente deterioro desde los años cincuenta.

Las concentraciones de negocios étnicos o centralidades étnicas más florecientes de Sydney, Chinatown, Little Italy y Asiatown, han sido promovidas no sólo por los propios emprendedores étnicos, sino también por las políticas municipales y hasta por inversores extranjeros. Así, los ayuntamientos han visto en la proliferación de negocios étnicos la vocación turística de esos barrios con restaurantes, venta de productos exóticos, etc. Ese destino turístico ha constituido no sólo un medio de renovación urbana, unida a la implantación de decoración exótica, puertas chinas, dragones, piazzas italianas, etc. por parte de inversores extranjeros coétnicos (chinos e italianos), sino también un medio de reducción del paro, gracias al mercado de trabajo étnico (Collins, 2006).

Li y sus colaboradores (2006) destacan el papel de los bancos étnicos en Estados Unidos, una realidad en absoluto novedosa: no en vano, la aparición de la primera institución financiera de origen japonés en California data de 1899. Estas instituciones, sobre todo las de origen chino, han colaborado en el desarrollo residencial (también empresarial, en el caso de los bancos coreanos) de sus coétnicos en ese país. Así, los bancos coreanos, tras las revueltas de Los Ángeles de 1992, ayudaron a los emprendedores coétnicos, gravemente afectados por los disturbios, con préstamos de hasta 100.000 dólares para revitalizar sus negocios. Por su parte, los bancos chinos han participado de forma importante en la transformación de la Chinatown tradicional en la ciudad de Los Ángeles y en la creación de los ethnoburbs o suburbios multirraciales y multiculturales en el vecino San Gabriel Valley. Los bancos chinos no sólo facilitan las iniciativas empresariales y las promociones residenciales de sus coétnicos en Estados Unidos, sino que, además, dado el carácter multinacional de sus clientes, les ayudan en sus business ventures de exportación e importación en los países del Pacific Rim (Li et alii, 2006).

4 Ferrer Regales (2006) también las denomina «microcentralidades»; Toubon y Messamah (1991), «centralidades inmigradas»; Kaplan (1998), ethnic central place; Wilson (2007), black business districts; Arreola (2007), ethnic shopping streets y Mexican downtown; Ma Mung (1998), territoires marchands centraux; Battegay (1992), quartiers centraux. Las expresiones ethnic business districts (Li, 1998, 2007, y Gober, 2000), espaces marchands ethniques (Dinh, 2006) o etbnic business areas (Vuddamalay, 2007) también me parecen equivalentes a la de «centralidades étnicas», aunque en inglés ethnic downtown tiene la ventaja de la brevedad. Waldinger et alii (1990) utilizan la expresión central business district of Chinatown (en Nueva York), local ethnic market o, simplemente, etbnic market y local retail enclave. Light y Gold (2000) hablan de los small business districts o business districts de los grupos étnicos; Godfrey (2007), de etbnic districts o urban ethnic landscapes o ethnic main street. Torres (2006), finalmente, describe el barrio de Russafa como centre de negocis étnics.

5 Prefiero la expresión «centralidades étnicas» a la de «centralidades minoritarias». La primera tiene más resonancias en la literatura sobre migraciones. Aunque la «etnicidad» no se limita a los grupos de inmigrantes, se suele vincular en muchos casos a estos colectivos. 
Para Airriess (2006), la ocupación por parte de vietnamitas ${ }^{6}$ de una zona comercial suburbana semiabandonada de Versailles, en New Orleans, es una ethnic gentrification:

"The reoccupation of derelict commercial space and the conversions from residential to commercial space are examples of what Loukaitou-Sideris $(2002,335)$ refers to as «ethnic gentrification» resulting from a reterritorialization of space to meet the various economic and cultural needs of the new ethnic-Vietnamese community.» (Airriess, 2006: 23)

Tal vez, sin embargo, el sentido que da Airriess a la ethnic gentrification tenga más que ver con una revitalización étnica. Little Tokio, en Los Ángeles, ha experimentado una ethnic gentrification de otro género, a través de empresas japonesas multinacionales. Esta «gentrificación étnica desde arriba» ha tenido resultados no deseados para los antiguos residentes de origen japonés en el barrio (Smith, 2006). La revitalización de Harlem en la década de 1990 también ha supuesto una ethnic gentrification protagonizada por acomodados negros americanos recién llegados al barrio (Godfrey, 2007).

En Manchester, se ha diseñado una Little Italy sin residentes de origen italiano con el ambiente de piazza y comercios y restaurantes italianos en un barrio popular donde en otro tiempo sí hubo inmigrantes italianos (Taylor, 2000). En Londres, las autoridades también han dado la «marca» Banglatown a Spitalfields, borough de Tower Hamlets, actual barrio de inmigrantes bengalíes, anteriormente barrio judío (Shaw et alii, 2004), con notable éxito, «excesivo» éxito tal vez, hasta el punto de que los habitantes inmigrantes del barrio están sufriendo las consecuencias de la gentrificación y de la folclorización de su identidad. En cualquier caso, los negocios étnicos se contemplan como un recurso, como una riqueza.

En ocasiones, sin embargo, se argumenta que las actividades económicas de los inmigrantes favorecen la aparición de guetos (Aramburu, 2000) o de guetos comerciales. La frecuente repetición de tipologías comerciales, el escaso sentido estético de los escaparates, los rótulos en idiomas diferentes del oficial, el ruido o la falta de higiene, entre otros aspectos, son motivos más o menos reales de quejas por parte, sobre todo, de comerciantes autóctonos y, en ocasiones, de vecinos del barrio donde se implantan los comercios étnicos. En ocasiones, estas reclamaciones son amplificadas por los medios de comunicación y los políticos locales y, a veces, ocasionan cambios significativos en las políticas comerciales locales, como la cancelación de aperturas de nuevos comercios de determinado tipo, controlados por sectores de emprendedores inmigrantes. Este

6 Utilizo en el artículo los nombres de las nacionalidades para no referirme exclusivamente a personas extranjeras — «vietnamitas» en este caso-, sino más bien a personas cuyo origen es esa nacionalidad, independientemente del pasaporte o pasaportes de que disponga. En consecuencia, por «vietnamitas» me refiero a «personas de origen vietnamita». 
tipo de tensión se puede observar, por ejemplo, en el caso de los comercios mayoristas textiles chinos en Barcelona, en el Eixample (también en otras zonas y tipos de comercios, como en Ciutat Vella: Serra, en prensa); en París, en La Roquette (Dinh, 2006); o en Madrid, en Lavapiés.

En cambio, Light y Gold (2000) subrayan, precisamente, que diversos autores que han estudiado las ciudades norteamericanas, como Jane Jacobs, William Foote Whyte, Gerald Suttle, William Kornblum y Fran Markowitz, valoran los small business districts donde se concentran los comercios de proximidad como los «ojos» que facilitan la seguridad y la atracción del barrio. Los negocios de los inmigrantes, en muchos casos, consisten precisamente en pequeños comercios. Además, en los barrios de inmigrantes, los comercios étnicos de proximidad desempeñan diversos papeles, como sedes informales de las organizaciones del barrio, lugares de intercambio de información sobre empleos y de interrelaciones personales, etc. Rath (2007) coincide con estas ideas. En Ciutat Vella, en Barcelona, los representantes de asociaciones de comerciantes que destacan aspectos positivos en relación con la presencia de los negocios étnicos destacan el factor portes obertes («puertas abiertas»); es decir, los inmigrantes emprendedores, desde la segunda mitad de los años noventa, han conseguido reabrir las puertas de locales comerciales que llevaban años cerradas en el barrio a causa de la crisis del pequeño comercio de proximidad. La abundancia de comercios abiertos en una calle suele mejorar la seguridad en el barrio, atrae a nuevos clientes, dota de servicios a la clientela local, etc.

La presencia de una intensa actividad económica debería descartar la idea de gueto, como también sostiene Goldring (2006), un intelectual residente en el barrio de inmigración africana de la Goutte-d'Or en París. Para él, este barrio no se ha convertido en un gueto gracias a los numerosos comercios y servicios de emprendedores que, en ocasiones sin ser residentes del barrio y ni siquiera africanos (existen comerciantes chinos que venden productos africanos), atraen a clientes africanos, magrebíes y antillanos de toda la conurbación parisina e, incluso, del extranjero (Battegay, 1992; Pinçon y Pinçon-Charlot, 2001). En cambio, otros barrios de inmigrantes de la banlieue parisina, sin apenas actividad comercial, para Goldring (2006), sí podrían merecer el calificativo de gueto. Para Raulin (2002), la ausencia de comercios en muchos lugares de los guetos de la banlieue parisina contrasta con la densidad de actividad comercial que se dan en otras zonas de la capital francesa, aunque periféricas, percibidas con poco acierto como guetos, como la Petite Asie. ${ }^{7}$ De forma similar, para Zhou (1992), la presencia de negocios de emprendedores chinos en la Chinatown de Manhattan evita la conversión de este barrio en un gueto más, como muchos barrios de minorías étnicas

7 Expresión de Raulin (1988). La denominación Petite Asie resulta más apropiada que otras como le quartier chinois, Chinatown o Chinatown-sur-Seine, que no expresan bien la composición multiétnica de los asiáticos del barrio, refugiados procedentes del sudeste asiático (Laos, Camboya y Vietnam). 
en Estados Unidos. ${ }^{8}$ Otras «demarcaciones», ${ }^{9}$ en ocasiones, son más consecuencia del peso político de un grupo étnico que de la realidad de una verdadera centralidad étnica. Así, la Little Ethiopia de Los Ángeles ha obtenido esta «marca» o reconocimiento por parte del Ayuntamiento en un barrio donde los comercios de origen etíope no constituyen la mayoría. Little Ethiopia tampoco es el lugar de máxima concentración de residentes etíopes en Los Ángeles, aunque no se encuentra lejos de esas zonas (Chacko y Cheung, 2006).

Para Chacko (2003), citado por Airriess (2006), la atracción de una centralidad étnica no es sólo comercial, sino que puede ir unida a otras de tipo social - ir a visitar a los amigos o parientes - o religiosa - ir al centro de culto, como es el caso de los pequeños oratorios musulmanes que existen en Ciutat Vella, en Barcelona, o el templo católico chino del recinto de la parroquia católica en la Petite Asie de París, o los centros de culto de tres religiones en la Goute-d'Or, o la iglesia de Mary Queen of Vietnam Church en el barrio de Versailles de New Orleans, etc.- . Chacko denomina a estos espacios con superposiciones de ámbitos ethnic sociocommercescapes.

La renovación del barrio que efectúan los inmigrantes no es sólo funcional, es decir, no se limita a las actividades económicas; por el contrario, también se puede analizar desde otros puntos de vista, como el residencial. ${ }^{10}$ Así, por ejemplo, los inmigrantes portugueses de Little Portugal, en Toronto, llevaron a cabo remodelaciones de viviendas en el barrio que ocuparon (Teixeira, 2006).

Las centralidades étnicas, concentraciones de negocios regentados por minorías étnicas y dirigidos en parte a ellas, ${ }^{11}$ suelen acompañarse de concentraciones de residentes coétnicos y de otros establecimientos, como los centros de culto. En cualquier caso, es indudable que la presencia de estos nuevos espacios de «centralidad» está modificando el espacio formal, social y funcional de muchas ciudades con una intensa inmigración. Espacios como los de Little Italy en Nueva York, las Chinatowns de diversas ciudades norteamericanas, ${ }^{12}$ los barrios o colonias latinos de Estados Unidos, las Little Tokyo, Koreatown, Little Armenia, Thai Town, Little Saigon y Little Ethiopia de Los Ángeles, la Little Havana en Miami, etc. se manifiestan también en espacios urbanos con redes de inmigrantes desde hace décadas, en Gran Bretaña y en Europa

\footnotetext{
8 Los orígenes históricos en Estados Unidos de las Chinatowns, de las Japantowns y de las concentraciones de negocios de negros en sus barrios están vinculados a la discriminación racista hacia los chinos, japoneses y negros, respectivamente (Anderson, 1987, citado por Smith, 2006; Henke, 2001, citado por Boswell y Jones, 2006).

9 Shaw et alii (2004) y Rath (2007) analizan la capacidad de los barrios de inmigrantes para convertirse en «recintos» o espacios delimitados para actividades turísticas.

10 Lo mismo se podría decir de otros aspectos, como la reutilización del espacio público, la reocupación de las aulas de las escuelas, etc., que superan el ámbito de este artículo. Ver estos aspectos en Aramburu (2000), para el caso de Ciutat Vella, en Barcelona.

11 Comercio comunitario, según expresión de Ma Mung y Guillon (1986: 125), dirigido a los inmigrantes residentes. 12 Sobre todo las de San Francisco (Godfrey, 2007), Nueva York (Zhuo, 1992), Los Ángeles (Li et alii, 2006) y Toronto (Lo, 2006).
} 
continental occidental. En este sentido, es muy probable que, en los próximos años, las principales ciudades del sur de Europa tiendan a experimentar fenómenos que ya han experimentado otras capitales europeas, tales como el Banglatown de Londres (Shaw et alii, 2004), la Little Italy de Manchester (Taylor, 2000) o las Petite Asie, Little Jaffna, Little India o el tchawke o lugar de encuentro paquistaní en París (Vuddamalay, 2007). En efecto, los enclaves chinos del sur de Europa son ya una realidad en el quartiere Sarpi de Milán (Cologna, 2006), en la plaza Garibaldi en Nápoles (Ma Mung, 2000), en el Eixample barcelonés (Beltrán, 2000) o en Lavapiés, en Madrid (Riesco, 2007), etc. Lo que singulariza cada una de esas centralidades étnicas no es tanto la población residente coétnica como los emprendedores étnicos, que dan un sentido identitario a esos espacios. ${ }^{13}$

\section{La geografía y las «minorías intermediarias», la «economía de enclave étnico» y la «economía étnica»}

Los estudios de sociología sobre los emprendedores inmigrantes han atendido a aspectos relativos a las características de los negocios étnicos: estrategias de movilidad social ascendente o bien de supervivencia en las condiciones de la economía dual, circunstancias familiares, financiación de los negocios, composición étnica y sexo de los empleados, el debate sobre la autoexplotación, etc. De alguna manera, estos estudios también se han interesado por la distribución geográfica de los negocios étnicos.

La centralidad étnica de Little Havana de Miami fue estudiada por Wilson y Portes (1980), quienes acuñaron la expresión «economía de enclave étnico» para referirse a ese territorio, y la vincularon a la concentración de emprendedores inmigrantes en una zona urbana delimitada. Otros autores han acunado expresiones como la de «minorías intermediarias» (Bonacich, 1973), o bien han preferido el concepto de «economía étnica» (Light y Gold, 2000).

El debate sobre el uso de estas expresiones no está cerrado; de hecho, no ha habido consenso entre los investigadores (Portes y Shafer, 2006). A este respecto, no pretendo extenderme en el comentario de este debate, tratado abundantemente en otras publicaciones. ${ }^{14}$ Me limitaré a comentar cuál es el enfoque que se da al debate sobre los procesos geográficos que intervienen en la localización de los negocios étnicos.

Para Bonacich (1973), las middlemen minorities se identifican con los emprendedores de un grupo étnico distinto de aquel al que sirven, y constituyen una minoría

13 Ma Mung (2000) se refiere a los espacios chinos, pero su sentido es aplicable a espacios de negocios de otros grupos étnicos.

14 Existen muchas referencias sobre este debate. Véase Portes y Bach (1985), Light y Gold (2000), Zhou (2004), Portes y Shafer (2006) y Checa y Arjona (2006). 
respecto al grupo predominante de la zona donde se ubican sus negocios. De ahí el interés de esos emprendedores por no «autoafirmarse» a través de la concentración, sino más bien por dispersarse.

Una estrategia diferente es la que se desarrolla en la «economía de enclave étnico» (etbnic enclave economy), que atiende más bien a criterios de concentración espacial de las empresas étnicas en una zona concreta (Wilson y Portes, 1980 y Portes y Bach, 1985). Sin embargo, ése no es el único requisito para poder calificar a una zona urbana como «economía de enclave étnico»; así, debe disponer también de un sector económico étnico diferente del mercado general, con un elevado capital humano, gracias al cual los emprendedores obtienen mayores beneficios que sus coétnicos que trabajan como empleados en los sectores económicos normales, no étnicos, como recuerdan recientemente Portes y Shafer (2006) a la comunidad científica.

La dificultad para validar empíricamente la hipótesis de la «economía de enclave étnico» conduce — insisten los mismos autores - a que, en realidad, apenas se pueda aplicar a otros casos distintos del de los cubanos exiliados de la primera generación entre las décadas de 1960 y 1970 (la generación posterior de los Marielitos queda excluida, como también ha subrayado Alberts, 2006) en el área metropolitana de Miami, y del Chinatown de Nueva York, estudiado por Zhou (1992). En este sentido, el concepto de «economía de enclave étnico» se estaría aplicando de forma inapropiada en otros casos, según Portes y Shafer, quienes se lamentan de la confusión en el uso de este concepto excesivamente popular allí donde no se dan las condiciones exigidas por los autores, como la existencia de una gran concentración y diversidad de emprendedores étnicos y un extenso mercado de trabajo étnico propio. En cualquier caso, los autores reconocen que validar empíricamente esas condiciones no es tarea sencilla. Tampoco queda claro cuáles son los umbrales de concentración y diversidad de emprendedores étnicos por encima de los cuales se puede afirmar que existe una «economía de enclave étnico».

Para Waldinger (1993), es precisamente la condición de la concentración geográfica lo que restringe excesivamente el concepto de economía de enclave étnico. Light y Gold también insisten en la dificultad de encontrar en la realidad casos que cumplan todos los requisitos del «enclave», lo que les lleva a proponer un concepto mucho más genérico, el de ethnic ecomomies:

«the concept of ethnic economy makes no claim about the locational clustering or density of firms, which might indeed, be evenly distributed among neighbourhoods and industries. The concept of ethnic economy is agnostic about clustering» (Light y Gold, 2000: 10) 
Así, las «economías étnicas» de Light y Gold incluyen a los emprendedores inmigrantes y a sus trabajadores coétnicos empleados.

En cualquier caso, habría que reconocer, de entrada, que se produce una concentración metropolitana - a escala pequeña, en relación con la superficie de un país - de la economía étnica: la mayoría de los inmigrantes se concentra en las ciudades. En una escala mayor, dentro de un área metropolitana, se puede producir o dispersión o concentración (centralidades étnicas) de los negocios étnicos, o ambos fenómenos a la vez. Tal vez el agnosticismo de Light y Gold derive de las múltiples definiciones y ajustes que ha recibido el concepto de «economía de enclave étnico», que los dos autores recogen, y de la frustración y la confusión que se puedan haber producido como resultado de estos ejercicios teóricos. El debate sobre el concepto de economía de enclave étnico ha llenado muchas páginas de publicaciones científicas, sin que haya sido posible alcanzar un consenso sobre qué es ni cuáles son sus límites geográficos (Alberts, 2006).

Las restricciones del concepto de economía de enclave étnico y de la pretendida aespacialidad de las economías étnicas no impiden que nos preguntemos cómo influye la geografía, cómo incluyen los procesos geográficos, en la configuración de los espacios donde se sitúan los negocios étnicos.

\section{Las relaciones espaciales entre barrios de inmigrantes y centralidades étnicas. Los procesos de concentración de emprendedores étnicos}

Waldinger y sus colaboradores (1990) lamentan que se haya prestado poca atención a la influencia de los factores geográficos en la localización de las actividades económicas de los inmigrantes. En términos similares se expresan Rekers y van Kempen (2000). Más recientemente, Kaplan y Lei (2006b) señalan que, dado que se han dedicado ya muchos estudios al papel del capital humano, social y financiero, ha llegado el momento de estudiar el papel del capital espacial en los negocios étnicos. Ma Mung utilizó en 1992 la expresión ressources spatiales para referirse a las estrategias espaciales empresariales de la diáspora china. Para Rath (2002), existen pocos estudios comparativos sobre los emprendedores étnicos que tengan como nivel de análisis la ciudad. Éste es el nivel que interesa destacar, ya que las condiciones sociales, demográficas, urbanísticas, políticas, etc. del contexto local, e incluso del barrio donde se insertan las actividades económicas de los grupos étnicos, importan tanto como los contextos en otras escalas, como la nacional o la global. Así, por ejemplo, si en la ciudad de Ámsterdam en 1997 no había apenas talleres textiles, un sector dominado hasta entonces por emprendedores de origen turco, se debía, entre otros factores, a que el Ayuntamiento obligaba al 
estricto cumplimiento de las regulaciones sobre contratación de mano de obra extranjera en esas empresas (Raes et alii, 2002).

Pese a su «agnosticismo», Light y Gold (2000) destacan la asociación espacial entre barrios étnicos (barrios de inmigrantes o de minorías) y concentraciones de negocios étnicos. Los ejemplos de Estados Unidos que facilitan esa asociación son los barrios históricos de italianos y polacos en Pittsburgh, Polonia en Detroit y Bronzeville en Chicago, así como ejemplos de promoción inmobiliaria étnica: barrios de judíos dispersos fuera de Manhattan (controlado por promotores inmobiliarios no judíos), en Brooklyn y en el Bronx; Chinatown en San Francisco, después del terremoto de 1906; el barrio chino de Monterrey Park, en el condado de Los Ángeles, a partir de 1977; Koreatown, en Los Ángeles; Harlem, para los afroamericanos; el suburbio de Oak Park, en Detroit, que contaba en 1955 con un 40\% de población judía.

En Pittsburgh, en cambio, la comunidad afroamericana se hallaba dispersa, pese a contar con asociaciones y negocios étnicos y dos periódicos en la ciudad. La falta de «control territorial», de «concentración geográfica», en un espacio de negocios propio (business district es la expresión que utilizan Light y Gold) dificultó a los negros recién llegados a Pittsburgh a principios del siglo xx la búsqueda de empleos, al tiempo que les privó de la seguridad y comodidad de un barrio propio. Light y Gold muestran que ni las comunidades ni las centralidades étnicas son siempre urbanas, como sucede en el caso de los católicos de origen alemán en el rural Midwest o de los rurales amish. En cualquier caso, estos dos autores señalan cómo la coincidencia geográfica y la correlación espacial de zonas residenciales étnicas y de centralidades étnicas se apoyan mutuamente.

Para Rekers y van Kempen (2000: 62), las concentraciones residenciales de inmigrantes y de negocios étnicos muestran con frecuencia una asociación geográfica:

«clusters of ethnic entrepreneurs often emerge when an ethnic population is concentrated in an urban area. Sometimes this clustering of firms reflects the availability of cheap premises or the presence of a daily street market»

Para Dinh (2006: 42) «les artisans et commerçants sont en grande majorité localisés dans les centres urbains et industriels notamment là où la population étrangère est nombreuse». Además, Dinh destaca los efectos de aglomeración espacialः en 1982, París reunía el 40\% de los comerciantes extranjeros de Francia, mientras que los comerciantes franceses en la capital francesa sólo suponían el 13\%.

En Toronto, la centralidad étnica portuguesa coincide con el Little Portugal. Por este motivo, ante la progresiva disminución de los efectivos inmigrantes portugueses, los emprendedores de origen portugués de Little Portugal se muestran pesimistas 
(Teixeira, 2006); los negocios étnicos portugueses dependen, por tanto, «excesivamente» de la demanda coétnica. En Berlín, las empresas de origen turco se concentran en los distritos de Kreuzberg, Wedding y Tiergarten, que cuentan con un alto porcentaje de residentes de esa misma nacionalidad (Hillmann, 2006). La población hispana de Phoenix, en Arizona, ha pasado del 13\% en 1980 al 34\% en 2000. Phoenix es la ciudad con más población latina en el sudoeste de Estados Unidos tras Los Ángeles. Esa población no se concentra sólo en inner-city barrios, donde constituye la mayoría de los residentes desde 1990, sino que cada vez más se dispersa en las zonas suburbanas del norte de la ciudad. En cualquier caso, en los barrios suburbanos o colonias, se produce asimismo una concentración de negocios orientados a los latinos (Oberle, 2006). Las centralidades étnicas también se manifiestan en pequeñas localidades, como en Treasure Valley, en Texas, con la colonia Little Mexico, donde se concentran residencias, negocios e instituciones mexicanas (Arreola, 2007).

La diversidad de las actividades económicas constituye un rasgo importante de las centralidades étnicas, que consisten, por tanto, no sólo en la concentración de pequeños comercios de proximidad para una clientela coétnica de barrio relacionados con la alimentación y la restauración, lavanderías, peluquerías, tiendas de ropa, locutorios, envío de remesas, tiendas de películas y música, etc., sino también de negocios más especializados o de mayor volumen, como joyerías, talleres, grandes supermercados, librerías, ópticas, tiendas de fotografía, medios de comunicación, profesionales de la medicina, del derecho y de la contabilidad, consultores, agencias de viajes, traductores, agencias inmobiliarias, etc. (Zhou, 1992; Collins, 2006; Godfrey, 2007; Raulin, 2000).

Waldinger et alii (1990) dedican un capítulo de su libro Ethnic entrepreneurs: Immigrant business in industrial societies a las relaciones espaciales entre los negocios étnicos de un grupo y la configuración residencial de ese mismo grupo. Estos autores denominan a las centralidades de negocios étnicos que atraen no sólo a clientes coétnicos del barrio, sino también a coétnicos de otros barrios, e incluso de fuera del municipio y de otras zonas del país, regional ethnic shopping centres. Es el caso de la concentración de 2.000 comercios vietnamitas de la Little Saigon en Westminster, en California (Airriess, 2007); de la Petite Asie de París; de las Chinatowns de Belgrave Road en Leicester, Soho en Londres y Liverpool, en menor medida; y de las de Manhattan y de Sydney. Por tanto, según la influencia o el alcance de las «centralidades étnicas», se las podría clasificar como «centralidades étnicas locales», «centralidades étnicas metropolitanas», «centralidades étnicas regionales», etc.

La Chinatown de Sydney atrae visitantes de origen chino de toda el área metropolitana, no sólo por sus comercios y servicios, sino también por sus profesionales, como médicos y dentistas; otro tanto ocurre con los italianos en la Little Italy de esa misma ciudad. Cada año visitan el Asiatown de Cambramatta, en Sydney, unas 350.000 per- 
sonas de toda Australia y del extranjero. En estas tres centralidades étnicas de Sydney muchos visitantes no coétnicos también se sienten atraídos por su ambiente festivo y exótico (Collins, 2006).

«Ethnic entrepreneurs and the ethnic economy are a defining aspect of Sydney as a cosmopolitan global city» (Collins, 2006: 146)

Pero ¿qué es antes: el barrio étnico o la centralidad étnica? Waldinger, McEvoy y Aldrich (1990) ofrecen un paralelismo entre el antiguo enclave judío residencial y textil en el Lower East End de Manhattan y la Chinatown en ese mismo emplazamiento. Según ellos, la industria textil del Lower East End de Nueva York fue la que atrajo la mano de obra inmigrante judía a finales del siglo XIX, que se instaló precisamente cerca de las industrias y almacenes, por los bajos salarios y la dificultad del transporte. Ahí surgió un barrio judío floreciente, que contaba con una centralidad étnica de más de 1.430 comercios en 1890 . Los protagonistas del barrio han cambiado a lo largo del tiempo, pero la dinámica es la misma: se mantiene la necesidad del Garment Center de la Séptima Avenida neoyorkina de disponer de mano de obra barata y flexible y cercana en el Lower East End. Actualmente es la mano de obra china, no la judía, la que abastece al centro de moda neoyorkino de la Séptima Avenida.

La mejora de los transportes metropolitanos y la necesidad de más espacio para las industrias condujeron a la dispersión tanto de la población judía como de las fábricas en el área metropolitana hacia finales de los años sesenta y principios de los setenta. Las fábricas del Lower East End se vaciaron y los precios de los alquileres de locales y almacenes bajaron. Paralelamente, hacia los años sesenta, los chinos neoyorkinos vieron el fin de sus negocios de lavanderías a mano - por cierto, muy dispersas-, a causa de la popularización de las lavadoras automáticas domésticas. Esto, unido a la saturación de los restaurantes chinos, les llevó a aprovechar los buenos precios de los locales vacíos del Lower East End y a concentrarse en mayor medida en la vecina Chinatown, para a partir de entonces iniciar su actividad textil, menos exigente en cuanto a inversión inicial que la restauración. Así, la producción textil china pudo seguir abasteciendo al cercano Garment Center. Más adelante, tuvo lugar una nueva ola de dispersión por parte de los chinos anteriormente instalados o recién llegados, que se desplazaron hacia nuevos enclaves metropolitanos residenciales y textiles en Flushing, Queens y en Sunset Park (Brooklyn). ${ }^{15}$ Sin embargo, los nuevos inmigrantes chinos, con menor cualificación profesional, mantuvieron Chinatown como destino preferido para vivir y trabajar. Desde entonces, el barrio ha mantenido tanto su centralidad textil como su centralidad turística, de ocio y comercial, tanto por los chinos que en él resi-

15 También en midtown, en Nueva York, como señala Zhou (2002). 
den como por la atracción que ejerce entre los coétnicos de los suburbios y entre los turistas (Waldinger et alii, 1990). La presencia asiática en la industria textil de Nueva York no se limita a principios de los años noventa a un porcentaje elevado de trabajadores (27\%), inferior por otra parte al 33\% de los hispanos: el número de las empresas textiles de origen chino pasó de 8 en 1960 a 480 a finales de los años ochenta (Zhou, 2002).

Los bancos étnicos del área metropolitana de Los Ángeles — sobre todo bancos chinos y coreanos - se han situado en los barrios con abundantes residentes coétnicos. Los bancos chinos han acompañado a los coétnicos residentes en su suburbanización, mientras que los bancos coreanos han permanecido en Koreatown. Pese a acompañar geográficamente a su demanda coétnica, los bancos chinos no se han dedicado exclusivamente a facilitar créditos financieros a las personas de origen chino, sino que funcionan como instituciones plenamente integradas en los procesos inversores del mercado general (Li et alii, 2006).

A pesar de lo expuesto a propósito de los ejemplos citados en esta sección, la existencia de concentraciones residenciales étnicas no implica siempre la localización de negocios coétnicos. Una de las excepciones más dramáticas en Estados Unidos, ya citada anteriormente, la constituyen los numerosos barrios de población afroamericana, que albergan pocos emprendedores negros (Wilson, 2007). Las causas pueden ser múltiples y complejas, y no parecen ser estrictamente atribuibles a los mayores índices de criminalidad que se dan en esos barrios (Kaplan y House-Soremekun, 2006). Harlem, en Nueva York, es una excepción desde los años noventa, pues se trata de un barrio afroamericano donde hay una gran variedad de negocios, espectáculos, hoteles, etc. de emprendedores negros, junto con sedes de instituciones e iglesias (Godfrey, 2007).

Por otra parte, para Gober (2000), la correlación entre una concentración residencial de inmigrantes y su centralidad étnica no está tan clara:

«There is little consensus about the degree to which ethnic businesses require residential concentrations to survive, in part because findings are based on case studies of different ethnic groups in different cities. At the one extreme is Li's (1998) characterization of the Chinese ethnoburb' in suburban Los Angeles as simultaneously an ethnic residential area and business district. At the other extreme is Wood's (1997) discussion of Eden Center, a thriving Vietnamese shopping district in suburban Washington, DC, that functions successfully without benefit of an ethnic residential concentration» (Gober, 2000: 86).

En efecto, la relación entre barrios étnicos y centralidades étnicas no es una regla fija que se pueda aplicar siempre, sino que existen excepciones. Así, puede haber ba- 
rrios étnicos que apenas cuenten con negocios coétnicos, y también puede suceder que haya centralidades étnicas o emprendedores étnicos dispersos sin una población residente coétnica en la misma zona. En definitiva, hay otros tipos de espacios de negocios étnicos distintos de las centralidades étnicas descritas hasta ahora, que siguen otras lógicas o procesos geográficos.

\section{Conclusiones}

No es extraño que sean las ciudades globales las que experimenten una creciente presencia de residentes inmigrantes y de actividades económicas dirigidas no sólo a la demanda coétnica, sino también a la importación y distribución de productos electrónicos y textiles (que reflejan los vínculos transnacionales de los emprendedores asiáticos, sobre todo), al turismo, a la confección textil, etc. Los procesos a escala microgeográfica que acabo de analizar se pueden poner en relación con procesos macrogeográficos, como la globalización económica, la inversión asiática en Estados Unidos — que se suma con frecuencia, a través de bancos asiáticos (Zhou, 2004), a los procesos de gentrificación en Chinatowns (Li, 2007) o en Little Tokyo (Smith, 2006) o en operaciones de centros comerciales (Li, 2007 y Airriess, 2007) - , la demografía mundial, los movimientos migratorios internacionales y las diásporas (Ma Mung, 2000) y el transnacionalismo. Los emprendedores inmigrantes invierten con frecuencia en su país de origen, además de enviar remesas, ${ }^{16} \mathrm{e}$ incluso llegan a mantener una vida de «astronauta» en avión, entre Estados Unidos y Asia (Waldinger y Tseng, 1992).

Cada grupo de emprendedores étnicos puede utilizar los procesos de concentración o de dispersión de la localización de los negocios como estrategias empresariales. En este sentido, el concepto de «economía de enclave étnico» se ha impuesto en la literatura de la sociología de las migraciones, pese a que Portes, uno de los autores de la expresión, destaca que con frecuencia no se utiliza correctamente. El concepto de «centralidad étnica» no pretende constituirse en alternativa al concepto de Portes. Incide, por el contrario, en un aspecto que la literatura sobre la economía étnica en general ha considerado hasta ahora de manera secundaria o insuficiente: la influencia de los factores geográficos en la configuración de los espacios de negocios étnicos.

El papel de la geografía en la configuración de los espacios residenciales étnicos y de los espacios de negocios étnicos se está redescubriendo en los últimos años, como muestra la publicación de tres libros colectivos sobre geografía étnica: Landscapes of the Ethnic Economy (Kaplan y Li, 2006a), Contemporary Ethnic Geographies in America (Miyares y Airriess, 2007a) y Race, Ethnicity, and Place in a Changing America (Frazier

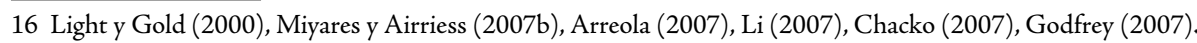


y Tettey-Fio, 2006). En estas obras colectivas hay un claro predominio de autores y casos norteamericanos, aunque se incluyen también algunos europeos. En cualquier caso, conviene insistir en la necesidad de profundizar en el fenómeno de las centralidades y de los emprendedores étnicos en las ciudades europeas en futuras investigaciones y publicaciones.

En las «centralidades étnicas» existe tanto una concentración de negocios étnicos como de residentes coétnicos que comparten el mismo espacio, como ocurre en las Chinatowns de New York y Los Ángeles, o la Banglatown, en Tower Hamlets, en Londres.

Las centralidades étnicas muestran que los barrios de inmigrantes y las concentraciones de negocios étnicos suelen presentar una correlación espacial. De todos modos, los espacios residenciales de inmigrantes no siempre suponen un factor de atracción para los negocios coétnicos. Así, la concentración de grandes supermercados y de numerosos comercios en el periférico barrio de la Petite Asie de París, donde la población asiática residente es minoritaria, o la presencia de grandes shopping malls chinos en los suburbios de Toronto, alejados de sus residentes coétnicos, son ejemplos de la conducta heterolocal (Zelinsky y Lee, 1998) de determinados grupos étnicos. Me ocuparé de estas excepciones a la correlación espacial a la que hecho referencia líneas más arriba en otro artículo donde describiré las centralidades étnicas minoritarias, las centralidades multiétnicas minoritarias, las centralidades étnicas especializadas y las zonas de emprendedores étnicos minoritarios.

\section{Bibliografía}

Airriess, C. (2007). «Conflict Migrants From Mainland Southeast Asia», en Miyares, I.; Airriess, C. Contemporary Ethnic Geographies in America. Rowman \& Littlefield, pp. 291-312.

Airriess, C.(2006). «Scaling Central Place of an Ethnic-Vietnamese Commercial Enclave in New Orleans, Louisiana», en Kaplan, D. H. y Li, W.. Landscapes of the Ethnic Economy. Plymouth: Rowman \& Littlefield, pp. 17-33.

Alberts, H. (2006). "Geographic Boundaries of the Cuban Enclave in Miami», en Kaplan, D. H. y Li, W. Landscapes of the Ethnic Economy. Plymouth: Rowman \& Littlefield, pp. 35-48.

Anderson, K. J. (1987). «The Idea of Chinatown: the Power of Place and Institutional Practice in the Making of a Racial Category». Annals of the Association of American Geographers, 77 (4): 580-598. 
Aramburu Otazu, M. (2000). Bajo el signo del Gueto. Imágenes del «inmigrante» en Ciutat Vella. Tesis doctoral. Barcelona: Departamento de Antropología Social, Universidad Autónoma de Barcelona. <http //www.tdx.cbuc.es/TESIS_UAB/AVAILABLE/TDX-1128101-090511/mao1de1.pdf> (3-12-2007)

Arreola, D. D. (2007). "Settlement Geographies of Mexican Americans», en Miyares, I.; Airriess, C. Contemporary Ethnic Geographies in America. Rowman \& Littlefield, pp. 93-122.

Barth, F. (1969). Ethnic Groups and Boundaries. The Social Organization of Culture Difference. Boston: Little \& Brown.

Battegay, A. (1992). «L'actualité de l'immigration dans les villes françaises: la question des territoires ethniques», Revue Européenne des Migrations Internationales, 8 (2), pp. 83-100.

Beltrán, J.; Oso, L.; Ribas, N.(2007). Empresariado étnico en España. Madrid: Observatorio Permanente de la Inmigración y Fundación CIDOB. <www.cidob.org> (3-12-2007).

Bonacich, E. (1973). «A theory of middlemen minorities», American Sociological Review, 38: 585-594.

Boswell, T. D.; Jones, T.-A. (2006). «The Distribution and Socioeconomic Status of West Indians Living in the United States», en Frazier, J. W. y Tettey-Fio, E. L. (eds.). Race, Etbnicity, and Place in a Changing America. Binghamton: Global Academic Publishing, pp. 155-180.

Bredeloup, S.; Bertoncello, B. (2006). «La migration chinoise en Afrique: accélérateur du développement ou «sanglot de l'homme noir»?», Afrique Contemporaine, 2 (218): 199-224.

Buckley, M. (2007). «Comercios y servicios de los inmigrantes en la Comunidad de Madrid: un enfoque geográfico», en Beltrán, J.; Oso, L.; Ribas, N. Empresariado étnico en España. Madrid: Observatorio Permanente de la Inmigración y Fundación CIDOB. Disponible en formato digital en www.cidob.org.

Chacko, E. (2007). «Immigrants from the Muslim World: Lebanese and Iranians», en Miyares, I.; Airriess, C. Contemporary Ethnic Geographies in America. Rowman \& Littlefield, pp. 313-330.

Chacko, E. (2003). «Ethiopian ethos and the making of ethnic places in the Washington metropolitan area», Journal of Cultural Geography, 20 (2): 21-42.

Checa, J. C.; Arjona Garrido, Á. (2006). «Economía étnica: teorías, conceptos y nuevos avances», Revista Internacional de Sociología, 45: 117-143.

Cologna, D. (2006). «L'immigrazione cinese in Italia: una realtà in rapida evoluzione», Aesse-Azione Sociale, 8. Disponible en <www.codiciricerche.it/download/ 
analisi/10\%20-\%20Immigrazione_cinese_in_Italia_-_una_realta_in_rapida-_evoluzione_DC_art.pdf> (3-12-2007).

Collins, J. (2006). «Ethnic Diversity and the Ethnic Economy in Cosmopolitan Sydney», en Kaplan, D. H. y Li, W. Landscapes of the Ethnic Economy. Plymouth: Rowman \& Littlefield, pp. 135-148.

Dinh, M. B. (2006). L'Entreprenariat ethnique en France et dans le monde anglosaxon. Paris: FASILD (Fonds d'Action Social pour l'Intégration et la Lutte contre les Discriminations), Direction des Etudes et de la Documentation.

Dinh, M. B. (2002). La petite Turquie, transposition de villages en situation migratoire. DEA de Geografía Urbana de la Université de Paris X-Nanterre.

DJergaïan, S. (2007). «Un territoire de l'identité arménienne. Le 9e arrondissement de París», Homes et Migrations, 1265, pp. 54-69.

Ferrer Regales, M. (2006). «Distribución, difusión y centralidad musulmanas en España», Estudios Geográficos, LXVII (261)ः 495-521.

Godfrey, B. J. (2007). «New Urban Ethnic Landscapes», en Miyares, I*; Airriess, C. Contemporary Ethnic Geographies in America. Rowman \& Littlefield, pp. 331-353.

Goldring, M. (2006). La Goutte-d'Or, quartier de France : la mixité au quotidien. París: Autrement Frontières.

Henke, H. (2001). The West Indian Americans. Wesport: Greenwood Press.

Hillmann, F. (2006). «Gendered Landscapes of Ethnic Economies. Turkish Entrepreneurs in Berlin», en KAPLAN, D. H. y LI, W. Landscapes of the Ethnic Economy. Plymouth: Rowman \& Littlefield, pp. 97-109.

Kaplan, D. H.; House-Soremenun, B. (2006). «Race, Space, Crime, and the African Entrepeneur: Business Owner Attitudes, Business Success, and the Neighborhood Context», en Kaplan, D. H. y LI, W. Landscapes of the Ethnic Economy. Plymouth: Rowman \& Littlefield, pp. 67-81.

Kaplan, D. H.; Li, W. (2006a). Landscapes of the Ethnic Economy. Plymouth: United Kingdom: Rowman \& Littlefield.

Kaplan, D. H.; Li, W. (2006b). «Introduction: The Places of Ethnic Economies», en Kaplan, D. H. y Li, W. Landscapes of the Ethnic Economy. Plymouth: Rowman \& Littlefield, pp. 1-16.

Kaplan, D. H. (1998). «The Spatial Structure of Urban Ethnic Economies», Urban Geography, 19 (6): 489-501.

LI, W. (2007). «Chinese Americans: Community Formation in Time and Space», en Miyares, Inés; Airriess, C. Contemporary Ethnic Geographies in America. Rowman \& Littlefield, pp. 213-232.

LI, W. (1998). «Anatomy of a new ethnic settlement: the Chinese Ethnoburb in Los Angeles», Urban Studies, 35 (1)ः 479-502. 
Li, W.; Dymski, G.; Chee, M. W. L.; Ahn, H.-H.; Aldana, C.; Zhou, Y. (2006). «How Ethnic Banks Matter: Banking and Community/Economic Development in Los Angeles», en Kaplan, D. H.y Li, W. Landscapes of the Ethnic Economy. Plymouth: Rowman \& Littlefield, pp. 113-134.

Lo, L. (2006). «Changing Geography of Toronto's Chinese Ethnic Economy», en Kaplan, D. H. y Li, W. Landscapes of the Ethnic Economy. Plymouth: Rowman \& Littlefield, pp. 83-96.

Loukaitou-Sideris, A. (2002). «Regeneration of urban commercial strips: Ethnicity and space in three Los Angeles neighborhoods», Journal of Architectural and Planning Research, 19 (4): 335-350.

Ma Mung, E.(2000). La diaspora chinoise: géographie d’une migration. París: GéOphrys, Ophrys.

Ma Mung, E.(1998). «Territorialisation marchande et négociation des identités: les Chinois à Paris», Espaces et Sociétés, 96: 145-162.

Ma Mung, E. (1996). «Entreprise économique et appartenance ethnique», Revue Européenne des Migrations Internationales, 8 (2).

Ma Mung, E.; Guillon, M. (1986). «Les commerçants étrangers dans l'agglomération parisienne», Revue Européenne des Migrations Internacionales, 2 (3): 105-134.

Miyares, I.; Airriess, C.A. (2007a). Contemporary Ethnic Geographies in America. Rowman \& Littlefield.

Pinçon, M.; Pinçon-Charlot, M. (2001). París mosäque. Promenades urbaines. París: Calmann-Lévy.

Portes, A.; Bach, R. L. (1985). Latin Journey: Cuban and Mexican Immigrants in the United States. Berkeley: University of California Press.

Portes, A.; Shafer, S. (2006). «Revisiting the Enclave Hypothesis: Miami Twenty-Five Years Later». The Center for Migration and Development, Princeton University Working Paper Series \#06-10.

Rath, J. (2007). "The Transformation of Ethnic Neighborhhods into Places of Leisure and Consomption». The Center of Comparative Immigration Studies. University of California, San Diego. Working Paper 144.

Rath, J. (2002). «Needle Games: A Discussion of Mixed Embeddedness», en RATH, Jan (ed.). Unravelling the Rag Trade: Immigrant Entrepreneurship in Seven World Cities. Nueva York: Berg, pp. 1-27.

Raulin, A. (2000). Lethnique est quotidien: diasporas, marchés et cultures métropolitaines. Paris: Connaissance des hommes, L'Harmattan.

Raulin, A. (1988). «Espaces marchands et concentrations urbaines minoritaires: la Petite Asie à París», Cahiers Internationaux de Sociologie, 85: 225-242. 
Rekers, A.; Van Kempen, R. (2000). «Location Matters: Ethnic Entrepreneurs and the Spatial Context», en Rath, J. (ed.). Immigrant business: the economic, political, and social environment. New York: Palgrave MacMillan, pp. 54-69.

Riesco Sanz, A.(2007). «Dimensiones y características de la empresarialidad inmigrante en Lavapiés (Madrid)». IV Congreso de la Inmigración. Valencia.

Singer, A. (2006). «The New Metropolitan Geography of Inmigration: Washington, D.C. in Context», en Frazier, J. W. y Tettey-Fio, E. L. (eds.). Race, Ethnicity, and Place in a Changing America. Binghamton: Global Academic Publishing, pp. 45-65.

Smith,J.M.(2006)+«Little Tokyo. Historical and Contemporary Japanese American Identities», en Frazier, J. W.y Tettey-Fio, E. L. (eds.). Race, Ethnicity, and Place in a Changing America. Binghamton: Global Academic Publishing, pp. 301-308.

Solé, C.; Parella, S. (2005). Los negocios étnicos. Los comercios de los inmigrantes no comunitarios en Cataluña. Barcelona: Fundació CIDOB.

Solé, C.; Parella, S.; Cavalcanti , Leonardo (2007). El empresariado inmigrante en España. Barcelona: Fundació La Caixa.

Teixeira, C. (2006). «Residential Segregation and Ethnic Economies in a Multicultural City: The Little Portugal of Toronto», en Kaplan, D. H. y Li, W. Landscapes of the Ethnic Economy. Plymouth: Rowman \& Littlefield, pp. 49-65.

Torres Pérez, F. (2007). Nous veïns a la ciutat. Els immigrants a València i Russafa. Valencia: Universitat de València.

Toubon, J. C.; Messamah, K. (1991). Centralité immigré. Le quartier de la Goutted'Or. L'Harmattan, CIEMI.

Vuddamalay, V. (2007). "Inner-city Ethnic Enclaves and Irregular Immigrant Networks as New Social Spaces in Global Cities: A Case-study of the 'Little India' of París», en Berggren, E.; Likić-Brborić, T.; Trimikliniotis, G.. Irregular Migration, Informal Labour and Community: a Challege for Europe. Maastrich: Shaker Publishing.

Waldinger, R.; McEvoy, D;; Aldrich, H. (1990). «Spatial dimensions of oportunitystructures», en WALdIngER, R.;Aldrich,H.; WARD, R.Ethnicentrepreneurs: Immigrant business in industrial societies. Newbury Park: Sage Publications.

Wilson, B. M. (2007). «The Hitorical Spaces of African Americans», en Miyares, I. y Airriess, C.A. Contemporary Ethnic Geographies in America. Rowman \& Littlefield, pp. 71-92.

Wilson, K.; Portes, A. (1980). «Immigrant Enclaves: An Analysis of the Labor Market Experiences of Cubans in Miami», American Journal of Sociology, 86, pp. 295-319.

Wood, J. (1997). «Vietnamese Place Making in Northern Virginia», Geographical Review, 87:58-72. 
Pau Serra del Pozo

Zноu, M. (2004). «Revisiting Ethnic Entrepreneurship: Convergencies, Controversies, and Conceptual Advancements», International Migration Review, 38, 1040-1074.

Zноu, M. (1992). New York's Chinatown: The Socioeconomic Potential of an Urban Enclave. Philadelphia: Temple University Press. 